\title{
Weight-loss practices among university students in Mexico
}

\author{
Pablo Méndez-Hernández • Darina Dosamantes-Carrasco • Michel Lamure • \\ Perla López-Loyo $\cdot$ Corín Hernández-Palafox • Dayana Pineda-Pérez • \\ Yvonne Flores • Jorge Salmerón
}

Received: 22 May 2008/Revised: 21 May 2009/Accepted: 17 November 2009/Published online: 15 December 2009

(C) The Author(s) 2009. This article is published with open access at Springerlink.com

\begin{abstract}
Objective To evaluate the prevalence of weight-loss practices among university students from Tlaxcala, Mexico. Methods A cross-sectional study of 2,651 university students was conducted. Logistic regression tests were used to estimate the probability of students trying to lose weight and successfully achieving weight loss.

Results Nearly $40 \%$ of students attempted to lose weight, though only about $7 \%$ lost more than $10 \%$ of their body weight and maintained this weight loss during the time of the study. The methods used most were exercise and dieting, and those who dieted were more successful at losing weight.

Conclusions The high prevalence of weight-loss attempts and the poor outcomes with these weight-loss methods among this sample of university students is a public health
\end{abstract}

P. Méndez-Hernández · D. Dosamantes-Carrasco · M. Lamure Equipe MA2D, Laboratoire ERIC, Université Lyon 1 et Lyon 2, Lyon, France

P. Méndez-Hernández ( $₫)$ · P. López-Loyo Facultad de Ciencias de la Salud, Universidad Autónoma de Tlaxcala, Calle 29 No. 820 Col. La Loma Xicohténcatl, 90062 Tlaxcala, Mexico

e-mail: pmendezh@hotmail.com

D. Dosamantes-Carrasco · C. Hernández-Palafox ·

D. Pineda-Pérez · Y. Flores · J. Salmerón

Unidad de Investigación Epidemiológica y en Servicios de

Salud, Delegación Morelos, Instituto Mexicano del Seguro

Social, Mexico City, Mexico

Y. Flores

UCLA Department of Health Services, School of Public Health and Jonsson Comprehensive Cancer Center,

Los Angeles, CA, USA concern. Universities should provide students with healthy weight-control approaches, which include offering information about healthier lifestyles, access to healthy food and opportunities to be physically active.

Keywords Attempts - Lose - Weight - University · Students · Mexico

\section{Introduction}

Obesity is a major public health problem worldwide. There is growing evidence that excessive body weight has serious consequences ranging from an increased risk of premature death to debilitating illnesses that decrease quality of life and health (Banegas et al. 2003; Bray 2006). As obesity becomes more prevalent, weight-loss practices grow increasingly popular in developed and developing countries. More than two-thirds of the adult population of the United States has attempted to lose or maintain weight (Serdula et al. 1999), and between 15 and 35\% of adults in Canada, Netherlands and the European Union are trying to lose weight at any given time (Smith et al. 2000). The proportion of adolescents and university students attempting to lose weight is even greater: $30 \%$ in Lebanon (Tamim et al. 2006), 23\% in Canada (Jones et al. 2001), 37\% in Japan (Kaneko et al. 1999) and $49.4 \%$ in Colombia (Alonso-Palacio et al. 2008).

Despite the potential benefits of weight loss, problems can arise from certain weight-loss practices. First, there is generally a low success rate for weight-loss maintenance through dieting (Garner and Wooley 1991). Second, repeat dieting is associated with cycles of weight loss and gain, which may pose a cardiovascular health risk (Jeffery 1996). Third, fluctuating weight and repeated diet failure is likely 
to lead to demoralization and depression (Brownell and Rodin 1994). Finally, preoccupation with dieting and body weight has been implicated in the development of eating disorders such as anorexia nervosa, binge eating disorder and bulimia nervosa (Wilson 1993).

Although preventing weight gain is seen as the essential first step toward reducing the prevalence of obesity, little is known about the weight-loss practices of Mexican university students. This information is crucial for planning and implementing public health initiatives against obesity. The aim of this study is to evaluate the prevalence of the specific weight-loss practices among students of the University of Tlaxcala, Mexico.

\section{Methods}

Study design and population

A cross-sectional study of 2,651 university students from the Autonomous University of Tlaxcala (AUT) was conducted between May and September 2004. Participants were selected from an official list of approximately 11,000 students. The sample was stratified by academic departments, and the number of participants selected from each department was proportional to its size. Random sampling was then used to select the participants from each department, and proportional numbers of students from each entrance year cohort were included.

\section{Study variables}

To evaluate weight-loss practices, we used an instrument comprised of questions on weight-control behaviour from the 1998 US National Health Interview Survey, as well as new questions developed by the study team. The content, relevance and clarity of the items in the instrument were then evaluated by three professionals in health-related fields. Finally, the questionnaire was pre-tested in a pilot study.

The first questions focused on the prevalence of weightloss attempts in the last year, including the question: "Have you tried to lose weight in the last year?" Study participants reported that they frequently used multiple weightloss methods, but the focus of this analysis is on the method that participants considered the most important, which was defined as the key method. Respondents were then asked to identify the key weight-loss method from a list of seven options: diet, exercise, medication, alternative medicine, health professional consultation (physician, nutritionist or psychologist), slimming products (creams, tea, pills, etc.), and recipes from books or magazines. Then, they selected their most important reason for choosing this key method from the following options: effective, easy, fast, less expensive, healthy, safe and promoted well-being.

Next, respondents were asked: "What is the reason you attempted to lose weight?" and were provided the following response: aesthetics or to keep up their physical appearance, self-esteem, to improve quality of diet, to prevent illness or to improve physical fitness. Respondents were also asked: "Have you used any extreme weightcontrol practices, such as vomiting or fasting?"

To evaluate the success of weight-loss attempts, the difference between weight reported before the use of the key method was compared to the participants' current weight. A weight-loss attempt was considered successful if participants lost at least $10 \%$ of their body weight, because weight loss on the order of $10 \%$ may have medical benefits (Kim et al. 2007; Lean et al. 1990). Additionally, the difference in body mass index (BMI) between before and after the weight-loss attempt, as well as between before the attempt and at the time the survey was completed was calculated.

Demographic data, including age, sex, marital status, education, student and familial income and occupation were obtained via a self-administered questionnaire. Anthropometric measures were obtained by trained personnel. Body weight was measured to the nearest $0.1 \mathrm{~kg}$ with a calibrated floor scale and height was measured to the nearest $0.5 \mathrm{~cm}$ using a stadimeter. BMI was calculated as a ratio of weight $(\mathrm{kg})$ to height $(\mathrm{m})$ squared, and the categories were defined according to the World Health Organization as follows: underweight $<18.5 \mathrm{~kg} / \mathrm{m}^{2}$, normal weight $18.5-24.9 \mathrm{~kg}$ / $\mathrm{m}^{2}$, overweight $25-29.9 \mathrm{~kg} / \mathrm{m}^{2}$, and obese $\geq 30 \mathrm{~kg} / \mathrm{m}^{2}$.

\section{Analysis}

Age-adjusted prevalence of the attempts to lose weight was estimated. Adjusted odds ratios and 95\% confidence intervals were computed using unconditional and multivariate logistic regression to evaluate the association between the two dependent variables (trying to lose weight or success of weight-loss attempts) and explanatory variables (age, sex, income, occupation and BMI). The covariates used to adjust the prevalence and odds ratio was age. The Wilcoxon signed-ranks test was used to evaluate the difference in BMI before and after the weight-loss attempt, and before the attempt and current BMI according to the different key weight-loss methods. Analyses were performed using STATA version 9.1.

\section{Results}

The study participants aged 17-45 years (mean 20.2 years; $\mathrm{SD}=2.6$ ), $62 \%$ are female, $29.2 \%$ of the students work, 
Table 1 Probability of trying to lose weight according to demographic and anthropometric characteristics $(n=2,651)$

\begin{tabular}{lll}
\hline Variables & OR $(95 \%$ CI $)$ & $p$ value \\
\hline $\begin{array}{l}\text { Sex } \\
\text { Men }^{\mathrm{a}}\end{array}$ & 1 & \\
$\quad$ Women & $2.7(1.9-4.1)$ & 0.000 \\
BMI & & \\
$\quad$ Normal/underweight & \\
$\quad$ Overweight & 1 & 0.000 \\
$\quad$ Obese & $3.1(2.6-3.8)$ & 0.000 \\
Student income & $5.4(3.7-7.9)$ & \\
$\quad<93$ dollars/month & \\
$\quad \geq 93$ dollars/month & 1 & 0.045 \\
Family income & $1.26(1.0-1.6)$ & \\
$<456$ dollars/month & & \\
$\geq 456$ dollars/month & 1 & 0.027
\end{tabular}

Odds ratios were adjusted by age

${ }^{a}$ Reference category

the mean income of students and of student family were 93 and 456 dollars per month, respectively. Also, $4.2 \%$ of the participants are underweight, $66.9 \%$ are normal weight and $28.9 \%$ are overweight or obese. The adjusted prevalence of attempting to lose weight within the last year was $38.8 \%$ (27.9\% in men and $45.6 \%$ in women). The principal reasons for attempting to lose weight were: aesthetics or keeping up appearance 57\%, and preventing illness $16 \%$. The prevalence of extreme weight-loss practices were: fasting $28.3 \%$, taking pills $4.6 \%$, consuming diuretics $2 \%$, and taking laxatives $1.6 \%$ (data not shown).

Table 1, reports the adjusted odds of trying to lose weight, which is 2.7 times greater for women than for men, 3.1 times greater for participants who are currently overweight and 5.4 times greater for who are currently obese than for those who are normal/underweight. Participants whose income was $\geq \$ 93$ per month were $26 \%$ more likely to try to lose weight than those with a lower income, and participants whose family income was $\geq \$ 456$ per month were $32 \%$ more likely to try to lose weight than those with a lower income.

Seventy-three percent of the participants who indicated that they had attempted to lose weight in the past year, also reported a key weight-loss method $(n=751)$. The principal reasons for using a key method were that participants viewed it as: healthy $24 \%$, effective $16 \%$, promoting wellbeing $15 \%$ and easy $9 \%$ (data not shown). Each key method was classified into one of three categories: (1) lifestyle, (2) medication and professional consultation, and (3) commercial products/services (Table 2).

In the lifestyle category, exercising was a key method reported by $68.3 \%$ and the most frequent forms of exercise were solitary exercise or exercise at the gym. Dieting was reported by $16.4 \%$ of the participants and the most frequent forms of dieting were: creating a personal diet (decreasing food portions, skipping meals, increasing vegetable consumption, or decreasing fat consumption), using fad diets, reducing intake of high calorie foods, and increasing consumption of low calorie foods. In addition, BMI after use

Table 2 Success and comparison of current BMI and BMI before and after key weight-loss method use $(n=751)$

\begin{tabular}{|c|c|c|c|c|c|c|c|c|c|}
\hline \multirow[t]{2}{*}{ Method used to lose weight } & \multirow[t]{2}{*}{$n(\%)$} & \multirow{2}{*}{$\begin{array}{l}\text { BMI before } \\
\text { method }^{\mathrm{a}} \text { (mean) }\end{array}$} & \multicolumn{2}{|c|}{ BMI after method } & \multicolumn{2}{|c|}{ BMI current } & \multicolumn{3}{|c|}{ Success of methods } \\
\hline & & & Mean & $p$ value & Mean & $p$ value & OR & $95 \% \mathrm{CI}$ & $p$ value \\
\hline \multicolumn{10}{|l|}{ Lifestyle } \\
\hline Diet & $123(16.4)$ & 27.1 & 25.3 & 0.000 & 23.8 & 0.000 & 3.0 & $1.7-6.4$ & 0.001 \\
\hline Exercise & $513(68.3)$ & 25.7 & 24.2 & 0.000 & 25.7 & 0.324 & 0.4 & $0.2-0.7$ & 0.001 \\
\hline \multicolumn{10}{|l|}{ Medication and consultation } \\
\hline Medication & $6(0.8)$ & 29.1 & 27.9 & - & 29.0 & - & & - & \\
\hline Alternative medicine & $14(1.9)$ & 29.7 & 26.2 & - & 27.7 & - & & - & \\
\hline Professional consultation & $27(3.6)$ & 25.3 & 24.1 & - & 27.1 & - & & - & \\
\hline All category & $47(6.3)$ & 28.0 & 25.5 & 0.000 & 26.8 & 0.232 & 0.6 & $0.2-1.3$ & 0.165 \\
\hline \multicolumn{10}{|l|}{ Commercial products/services } \\
\hline Slimming products & $49(6.5)$ & 25.3 & 23.4 & - & 25.6 & - & & - & \\
\hline Books/magazines & $19(2.5)$ & 27.1 & 26.0 & - & 26.7 & - & & - & \\
\hline All category & $68(9.0)$ & 25.3 & 23.4 & 0.000 & 25.1 & 0.734 & 0.2 & $0.1-0.7$ & 0.017 \\
\hline
\end{tabular}

Wilcoxon signed-rank test was used to assess the BMI's difference between before and after weight-loss attempt, as well as between before method use and current BMI. Logistic regression test was used to assess the success of each key weight-loss method; odds ratios were adjusted by age. The reference category was users of other methods

${ }^{a}$ Reference category 
of exercise and diet was lower than BMI before ( $p<0.000)$; but, only diet users tended to maintain their weight-loss and have current BMIs that were lower than BMI before use of their key method $(p<0.000)$ (Table 2$)$.

In the medication and consultation category, the most frequently used key methods were: seeking help from a health professional $(3.6 \%)$ and using alternative medicine $(1.9 \%)$. BMI after use of these methods was lower than BMI before $(p<0.000)$; however, users of these methods tended not to maintain their weight-loss, and their current BMI was not lower than BMI before use methods (Table 2).

In the commercial products/services category, the most used methods were: slimming products (6.5\%) and following recipes from books and magazines $(2.5 \%)$. BMI after use of these methods was significantly lower than BMI before use $(p<0.000)$; however, these users tended not to maintain their weight-loss, and their current BMI was not lower than BMI before use of these methods (Table 2).

Among students who reported using a key method to lose weight, only $7 \%$ lost more than $10 \%$ of their body weight and maintaining this weight loss to the time of the study. Table 2 also shows the relative success of each method: the students who dieted were three times more successful than users of other methods, while those who exercised were less likely to succeed $(\mathrm{OR}=0.4,95 \% \mathrm{CI}$ 0.2-0.7). Students who used commercial products/services were also less successful, than users of other methods $(\mathrm{OR}=0.2,95 \%$ CI $0.1-0.7)$.

\section{Discussion}

In this study, nearly $40 \%$ of participants had attempted to lose weight in the last year. Women, overweight, obese and higher income students were more likely to try to lose weight. Our findings are consistent with other studies showing that thinness has become a social norm among young people around the world (Tamim et al. 2006). The prevalence of attempting to lose weight in this study was $18 \%$ greater than university students from Lebanon (Tamim et al. 2006), 10\% lower than university students from Colombia (Alonso-Palacio et al. 2008), 15\% greater than teenaged girls from Canada (Jones et al. 2001) and close to that of adolescents from Japan (Kaneko et al. 1999). The norm of thinness seems to be particularly powerful among young people and women. In this population of university students, the most important reasons for attempting weight loss were aesthetics or appearance, while in adult populations, health is the most important reason for attempting weight loss (O'Brien et al. 2007). In addition, our findings are consistent with those of other studies that show that intentional weight loss is more common among young women and it is associated with aesthetics (Keski-Rahkonen et al. 2005).

Our finding that the most common weight-loss methods were exercise and dieting is consistent with weight-loss practices among university students from Lebanon and Colombia (Tamim et al. 2006; Alonso-Palacio et al. 2008). In addition, the most frequently extreme weight-control practices were similar to those used by Colombian students: fasting, medication, diuretics and laxatives (AlonsoPalacio et al. 2008).

Close to $7 \%$ of the students reported a weight loss of more than $10 \%$ of their body weight. Exercise alone was unsuccessful for achieving significant body weight reduction. The failure of exercise alone to cause lasting weight loss may be due to the fact that most students engaged in solitary exercise, which has been found not to promote continued or successful exercising in the adult Mexican population (Acosta-Cázares et al. 2006). Instead, those participants who dieted were the most successful at losing weight. This finding is consistent with other studies and reviews showing that dieting to lose or maintain weight is most successful; but diet achieves the best long-term results, when accompanied by regular exercise (Shaw et al. 2006; Kruger et al. 2006).

One limitation of this study is that the success of weightloss tactics was evaluated with self-reported weight change. However, we mitigated the presence of inaccuracies in participants' memory by asking only about their use of their key weight-loss method over the past year. Another limitation is the fact that $27 \%$ of the students who indicated that they had tried to lose weight in the past year did not indicate a key weight-loss method.

We found that the university students in our study have a high prevalence of overweight and obesity, and that most weight-loss practices do not mitigate obesity. For these reasons, we believe that university authorities in Mexico could help students to avoid unhealthy weight gain or to lose unwanted weight by providing a healthy weight-control approach, which includes information about healthier lifestyles (Lumbreras-Delgado et al. 2009), access to healthy food in the university environment, and increased opportunities to be physically active.

Open Access This article is distributed under the terms of the Creative Commons Attribution Noncommercial License which permits any noncommercial use, distribution, and reproduction in any medium, provided the original author(s) and source are credited.

\section{References}

Acosta-Cázares B, Aranda-Álvarez JG, Reyes-Morales H (2006) Patrones de actividad física de la mujer y del hombre. Rev Med Inst Mex Seguro Soc 44(Suppl 1):S79-S86 
Alonso-Palacio LM, Pérez MA, Alcalá G, Lubo-Gálvez A, Consuegra A (2008) Comportamientos de riesgo para la salud en estudiantes colombianos recién ingresados a una universidad privada en Barranquilla (Colombia). Salud Uninorte 24(2):235-247. Available via SCIELO. http://www.scielo.org.co/scielo.php?pid=S0120$55522008000200009 \&$ script=sci_arttext\&tlng=es. Accessed 17 May 2009

Banegas JR, López-García E, Gutiérrez-Fisac JL, Guallar-Castillón P, Rodríguez-Artalejo F (2003) A simple estimate of mortality attributable to excess weight in the European Union. Eur J Clin Nutr 57:201-208. doi:10.1038/sj.ejen.1601538

Bray GA (2006) Medical consequences of obesity. J Clin Endocrinol Metab 89(6):2583-2589. doi:10.1210/jc.2004-0535

Brownell KD, Rodin J (1994) Medical, metabolic, and psychological effects of weight cycling. Arch Intern Med 154:1325-1330

Garner DM, Wooley SC (1991) Confronting the failure of behavioral and dietary treatments for obesity. Clin Psychol Rev 11:729780. doi:10.1016/0272-7358(91)90128-H

Jeffery RW (1996) Does weight cycling present a health risk? Am J Clin Nutr 63(Suppl 3):452S-455S

Jones JM, Bennett S, Olmsted MP, Lawson ML, Rodin G (2001) Disordered eating attitudes and behaviours in teenaged girls: a school based study. CMAJ 165:547-552

Kaneko K, Kiriike N, Ikenaga K, Miyawaki D, Yamagami S (1999) Weight and shape concerns and dieting behaviors among preadolescents and adolescents in Japan. Psychiatry Clin Neurosci 53:365-371. doi:10.1046/j.1440-1819.1999.00559.x

Keski-Rahkonen A, Neale BM, Bulik CM, Pietiläinen KH, Rose RJ, Kaprio J, Raissanen A (2005) Intentional weight loss in young adults: sex-specific genetic and environmental effects. Obes Res 13:745-753. doi:10.1038/oby.2005.84

Kim J, Park SK, Lim YJ (2007) Analysis of the factors affecting the success of weight reduction programs. Yonsei Med J 48:24-29
Kruger J, Blank HM, Gillespie C (2006) Dietary and physical activity behaviors among adults successful at weight loss maintenance. Int J Behav Nutr Phys Act 19:17-24

Lean MEJ, Powrie JK, Anderson AS, Garthwaite PH (1990) Obesity, weight loss and prognosis in type 2 diabetes. Diabet Med 7:228 233

Lumbreras-Delgado I, Moctezuma-Ayala MG, Dosamantes-Carrasco LD, Medina-Hernández MA, Cervantes-Rodríguez M, LópezLoyo MRR, Méndez-Hernández P (2009) Estilo de vida y riesgos para la salud en estudiantes universitarios: hallazgos para la prevención. Revista Digital Universitaria 10:1-12. Available at http://www.revista.unam.mx/vol.10/num2/art12/art12.pdf. Accessed 21 May 2009

O'Brien K, Venn BJ, Perry T, Green TJ, Aitken W, Bradshaw A, Thomson R (2007) Reasons for wanting to lose weight: different strokes for different folks. Eat Behav 8:132-135. doi: 10.1016/j.eatbeh.2006.01.004

Serdula MK, Mokdad AH, Williamson DF, Galuska DA, Medlein JM, Heath GW (1999) Prevalence of attempting weight loss and methods for controlling weight. JAMA 282:1353-1358. doi: 10.1001/jama.282.14.1353

Shaw KA, Gennat HC, O'Rourke P, Del Mar C (2006) Exercise for overweight or obesity. Cochrane Database Syst Rev 4:112-117. doi:10.1002/14651858.CD003817.pub3

Smith CF, Burke LE, Wing RR (2000) Vegetarian and weight-loss diets among young adults. Obes Res 8:123-129

Tamim H, Tamim R, Almawi W, Rahi A, Shamseddeen W, Ghazi A, Taha A, Musharrafieh U (2006) Risky weight control among university students. Int J Eat Disord 39:80-83. doi:10.1002/ eat. 20205

Wilson GT (1993) Relation of dieting and voluntary weight loss to psychological functioning and binge eating. Ann Intern Med 119:727-730 